\title{
A model for facilitation of critical reflective practice
}

EJ van Aswegen, D. Litt. Et. Phil, Medunsa

HIL Brink, D. Litt. Et. Phil, Unisa

PJN Steyn, D. Litt. Et. Phil, Unisa

Figure 1 : Phases and flow of the inquiry

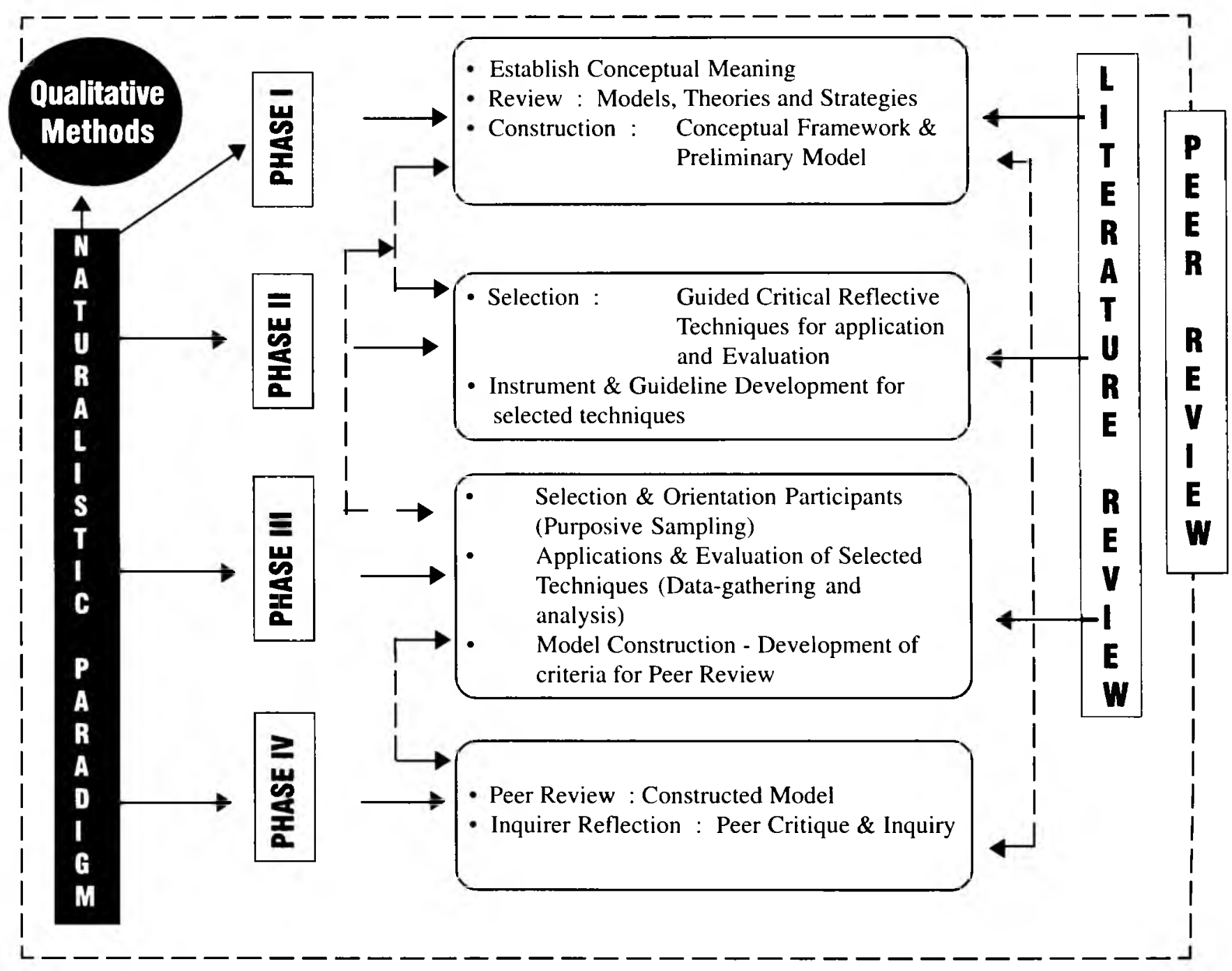

Due to the poor quality in the December 2000 issue three diagrams are reprinted. We apologise for the inconvenience. 
Figure 2 : A model for facilitation of Critical Reflective Practice

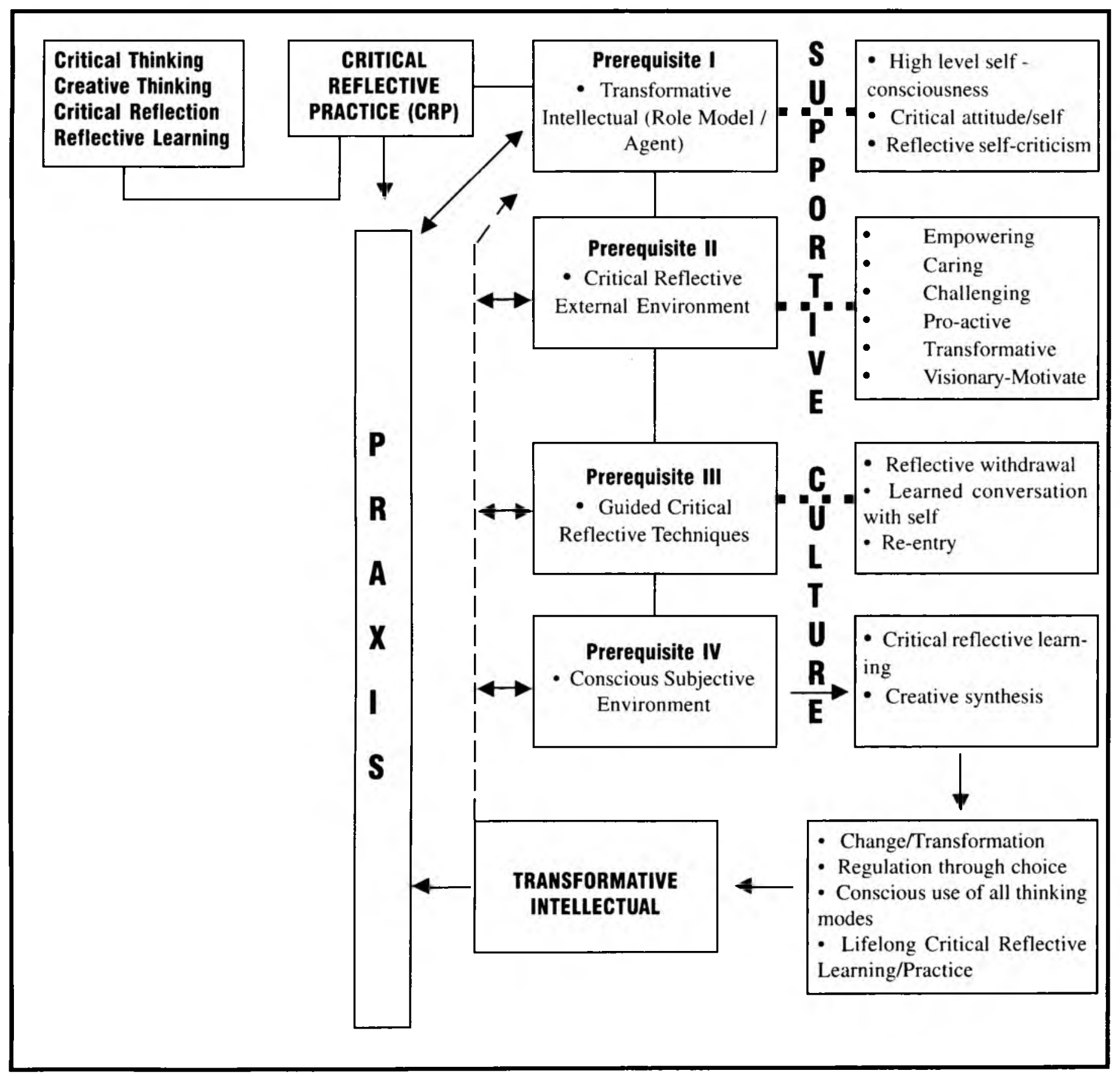



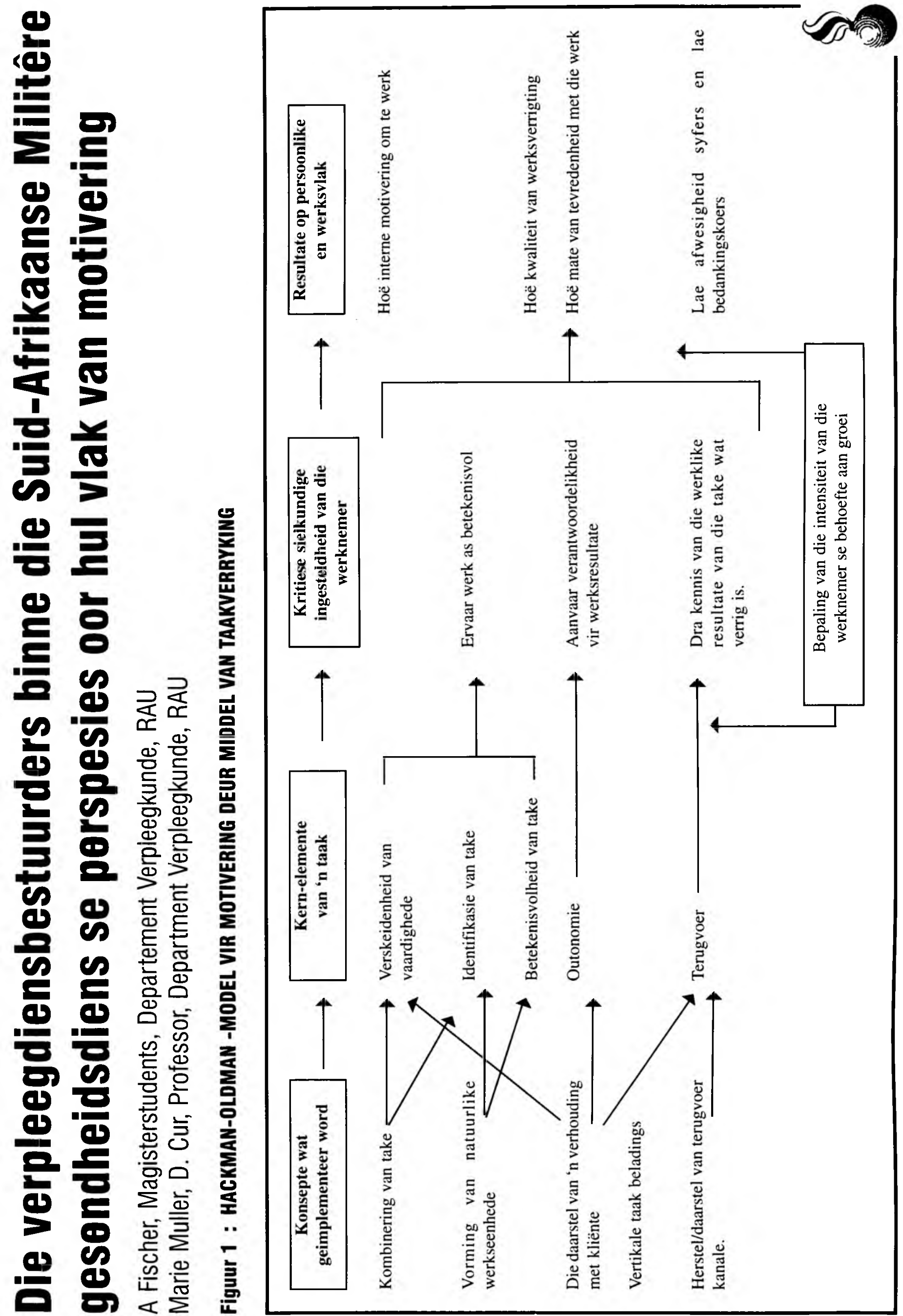


\title{
A model of facilitative communication for the support of general hospital nurses nursing mentally ill people
}

\author{
Part I: Background, Problem Statement and Research Methodology
}

\author{
TR Mavundla, D Cur, Centre for Institutional Excellence \& Research, Technikon SA \\ M Poggenpoel, D Phil, Department of Nursing Science, RAU \\ A Gmeiner, D Cur, Department of Nursing Science, RAU
}

\section{Abstract}

The impressive growth in the extent and range of psychiatric services provided by general hospitals in South Africa creates stress among nurses employed in these settings who are not psychiatric trained. This manifests itself in negative attitudes displayed towards mentally ill people.

The aim of this paper is to discuss the process followed in the development of the model of facilitative communication. A theory generative design was used. The research methods were dealt with in four steps of theory generation as set out below.

Step 1 entailed concept analysis. This step was dealt with in two phases, namely concept identification and concept definition. During concept identification, a qualitative research strategy that is explorative, descriptive and contextual was used. This was achieved through field research conducted in an urban general hospital. A sample of twelve professional nurses was selected from a population of 800 professional nurses employed in a general hospital using the purposive sampling technique. This sample size was determined by saturation of data in themes. Both semi-structured individual phenomenological interviews and observations were used as methods of data collection. Giorgi's method of descriptive data analysis (1985) was used. Four themes emerged from the results of the study. The main concepts of the model were identified and classified using a survey list of Dickoff et al. (1968). Step 2 dealt with the creation of interrelationship statements between concepts identified in Step 1, while Step 3 dealt with the description of the model using strategies proposed by Chinn and Kramer (1991). In Step 4, the description of guidelines for operationalising in practice was ensured. To ensure valid results, a model for trustworthiness proposed by Guba (Lincoln \& Guba, 1985) was used. The following criteria for trustworthiness were applied in all the steps of theory generation: truth value, applicability, consistency and neutrality.

\section{Background and motivation}

Over the past two decades, there has been an impressive growth in the extent and range of psychiatric services provided by general hospitals. This growth has been particularly evident in the increasing number of psychiatric patient units operated by the general hospitals. The American Hospital Association has recorded an increase in the number of such units from 664 in 1970 to 1432 in 1990 (Olfson, 1993:273). In South Africa, the researcher has noticed that almost all urban-based general hospitals possess psychiatric units, whereas in rural areas one finds medical-surgical units that admit psychiatric emergencies in the case of relapsed patients.

The expansion of general hospital in-patient care is attributable to a number of problems, some of which as yet remain unresolved. Solombela and Uys (1994:24) identify a high rate of relapse among Transkeian patients owing to distance from clinics and a lack of insight on the part of these patients into their condition. Olfson (1993:277) highlights the reduction in the number of beds in public mental hospitals, the changing role of general hospital psychiatric emergency rooms, and a growing emphasis on medical treatments, whilst NkonzoMtembu (1994:50) reveals the use and abuse of alcohol among African adolescents residing in KwaZulu-Natal as a cause of increased admissions to hospitals. Therefore, an increase in patient admissions in these settings is a distinct likelihood.

In spite of the expansion of general hospital in-patient care, the education of general practitioners in psychosomatic medicine remains steeped in controversy. Sivik (1992:375) argues that the education of medical students and physicians is still within a dualistic and reductionistic paradigm that not only refutes the concept of a human being as constituting a unit, but also sets apart the body from the mind. Although this approach persists in the training of physicians, a study of internal and family medicine residents has revealed that they experience difficulties in identifying psychosocial distress, despite having received training in behavioural medicine (Rosenberg, Commerford \& Driever, 1991:529). 
Poor education coupled with the inability of physicians to identify psychosocial distress has resulted in poor mental health services world-wide. Therefore, Abiodun (1990:273) argues that from this dearth of mental health personnel and facilities has emerged an urgent need to integrate mental health care with general health services in African countries. He sees this strategy as a viable method of extending mental health services throughout the African continent. In South Africa the integration process is currently being implemented, albeit without appropriate support for nurses employed in these settings.

Whilst the health providers are responding well to the call to integrate mental health care into the general health services, the attitudes displayed towards mentally ill people in these settings are getting worse. Mavundla (1993:30) reveals that about $90 \%$ of nurses in general hospital settings harbour negative attitudes, and less than $10 \%$ have a positive attitude towards the mentally ill. These findings are supported by Khanyile's argument (1992:27), in which she states that fellow nurses and physicians not employed in the psychiatric unit tend to refer to patients as "mad people". She further refers to this as causing stress and the increase in the incidence of " burnout" syndrome among nurses attached to the psychiatric unit. The seriousness of the existing situation in these settings cannot be overstated.

Apart from negative attitudes displayed towards the mentally ill, intra-institutional relations present yet another disturbing problem. One critical factor is the collegial relationship between psychiatric staff on the other hand and non-psychiatric consultants and nurses on the other. This has resulted in patients with ambiguous dual diagnoses being refused admission at psychiatric units despite stable vital signs (Dolinar, 1993:14). Dolinar further indicates that if such patients had been in the psychiatric unit they would have received intensive psychiatric care, which is impossible or unavailable in medical-surgical units.

Given the magnitude of these problems, one wonders how the prevailing situation may be rectified. In an effort to resolve these issues, health professionals responded with an array of strategies, some of which integrated the psychiatric component with basic educational programmes, while others led to the development of models intended to improve the situation. In South Africa, psychiatric nursing has been phased into the basic educational programme (Mavundla, 1993:3). Several studies conducted in Europe and Africa revealed a slight but positive change in the attitudes of health personnel following the introduction of a psychiatric component in the nursing curricula (Olade, 1989:93; Chinnayya et al., 1990:307).

Apart from the integration of mental health into the general health component, several models have been developed to improve practice. Among these, a model of counselling medically ill people proposed by Pollin (1992: 1S), and one of integrating mental health and primary care services for families with HIV proposed by Feingold and Slammon (1993:23) were developed. In South Africa, a model for psychiatric nursepatient interaction facilitating mental health has been developed by Poggenpoel (1994:51), while Greef and Poggenpoel (1993:23) developed a model of psychiatric nursing accompa- niment of patients with mental discomfort. While it is true that these models are appropriate for general settings, they cannot be used for mobilising support for general hospital nurses nursing the mentally ill. Therefore, a gap in the body of knowledge still exists. The researchers believe that the conceptualisation of a model of support to assist general hospital nurses to mobilise appropriate resources in the process of nursing mentally ill people will facilitate the promotion, maintenance and restoration of mental health as an integral part of health/wholeness. This background led to the following statement of the research problem.

\section{Problem statement}

While working in a general hospital psychiatric unit (1992 1994), the researcher encountered a number of problems regarding the care of mentally ill patients. One Saturday morning, while still busy with the ward routine, he received a phone call from a sister on duty in a surgical unit. She wished to transfer a patient she referred to as a suicidal psychiatric case. When he agreed to the request for the transfer, two other nurses who were on duty objected to the patient's being sent over to the psychiatric unit. They claimed that, according to policies enforced within the ward, no psychiatric patient could be transferred to the psychiatric unit over a weekend. Interestingly enough, it was a psychiatric consultant who had authorised the transfer.

After a lengthy altercation between the nurses in the psychiatric unit and those in the surgical unit, the patient was eventually transferred to the psychiatric unit. After assessing the subject of the inter-unit friction, the researcher concluded that the patient did in fact have suicidal tendencies, and had him admitted to the psychiatric unit. Originally, this patient had been admitted for surgery that was to be performed the following Monday. When the sister responsible was questioned on the subject of not telling the truth regarding the client's condition, she revealed that she feared keeping a psychiatric patient in her unit while there was a psychiatric unit in the hospital.

In the same hospital, it is possible that any number of nurses in both the psychiatric unit and medical-surgical units will have had similar experiences. It is therefore important to note that these experiences interfere with both patients' and nurses' quests for mental health as an integral part of wholeness. Therefore, taking care of the mentally ill in a general hospital may generate stress among those involved in this triad: nurses in the psychiatric unit, nurses in the medical-surgical units, and their patients. The above-mentioned problem, therefore, raised the following questions for this research:

\section{Research questions}

1. What are the experiences of those entrusted with the nursing of the mentally ill in a general hospital?

2. How could these nurses be supported?

The above research questions can be understood only in the light of the appropriate statement of the purpose of the research as set out below.

\section{Purpose of the research}

The main purpose of this research is to describe a model of 
support to assist general hospital nurses to mobilise the appropriate resources in the process of nursing mentally ill patients, thereby promoting a positive and accepting atmosphere amongst these nurses that facilitates mental health as an integral part of health/wholeness.

\section{Sub-Purposes}

To achieve the research purpose stated above, the following four sub-purposes were presented:

- To explore and describe the general hospital nurses' experience of nursing mentally ill people in order to identify concepts for the proposed model (Step 1)

- To construct specific interrelationship statements between the concepts identified in Step 1 (Step 2)

- To describe a model of support to assist these nurses to mobilise appropriate resources in the process of nursing mentally ill people within a general hospital from results of the field research obtained in step 1 of this research (Step 3)

- To establish guidelines that will help the advanced psychiatric nurse operationalise this model in the instruction, practice and research of nurses within a general hospital setting (Step 4)

To achieve the above sub-purposes and to give the results of this research structure, the researcher pursued specified paradigms as follows:

\section{Theories and models}

Field work was conducted with no pre-set theoretical frame of reference by using bracketing and intuiting. After data analysis, the results were discussed as patterns of interaction of the Nursing for the Whole Person Theory. This paradigmatic perspective of research consisted of meta-theoretical, theoretical and methodological assumptions. These assumptions of the Nursing for the Whole Person Theory (Oral Roberts University: Anna Vaughn School of Nursing, 1990:196; Rand Afrikaans University: Department of Nursing, 1992:6) were used to guide this research. On the other hand, the research methodology followed the research model in nursing proposed by Botes (1995:3). She states that the activities of the discipline of nursing take place in three orders, which are interrelated and which influence each other, as has been stated above (Botes, 1995:4).

\section{The theoretical definitions}

The following theoretical definitions are important in understanding the terminology used in this research:

\section{Nursing}

Nursing is a goal-directed service to assist the individual, family and/or community in the promotion, maintenance and restoration of health. Central to this service is the concept of nursing for the whole person (Oral Roberts University, 19881989:196; Rand Afrikaans University, Department of Nursing Science, 1992:6). In this research it refers to nursing rendered to a mentally ill person within a general hospital.

\section{Advanced psychiatric nurse}

An advanced psychiatric nurse is a nurse who has been awarded a clinical Master's degree in psychiatric nursingwith additional clinical experience under the supervision of a psychiatric nurse specialist and/or field specialist in another related discipline. He/She has an in-depth knowledge of, and skills in, advanced psychiatric nursing (Greef \& Poggenpoel, 1993:24).

\section{General hospital psychiatry}

This refers to the teaching of psychiatry as it relates to medical, surgical, obstetrics and paediatric units (Bell, 1991:1). In this research it denotes the nursing of mentally ill people within a general hospital setting.

\section{General hospital nurses}

General hospital nurse as a term of reference includes any nurse working in a general hospital setting who, at one time or another, renders nursing care to mentally ill people within his/ her department. He/She should not be registered with the South African Nursing Council as a psychiatric nurse.

\section{Dual diagnosis}

This means the presence of both a physical and mental illness in a patient who presents himself/herself for treatment in a general hospital setting (Mavundla, 1993:3).

\section{Support}

Support is described by Schoenhofer (1984:218) as a general method of assistance. In this research it refers to support rendered by advanced psychiatric nurses to nurses nursing mentally ill people in general hospital settings, assisting them to mobilise appropriate resources in the process of nursing mentally ill people, thereby facilitating the promotion, maintenance and restoration of the mental health of patients as an integral part of health or wholeness.

\section{Mentally ill person}

A mentally ill person is anyone presenting himself/herself with a dual diagnosis in a general hospital setting.

\section{Model}

Botes (1995:4) describes a model as a conceptual framework that classifies manifestations in terms of structures and that systematises the relationships between the manifestations and variables. A model therefore offers an account of the dynamics of the manifestations by way of a simple portrayal of the relationships between the main elements of the process. A model is the forerunner of a theory. According to Dickoff et al. (1968:420), it should therefore comply with a "level three" theory (e.g. a situation-relating theory).

\section{The research design}

A theory-generative research design using a qualitative research strategy that is more explorative in nature resulted in the description of a practice model, which was then contextualised within a specified general hospital setting in an urban area of KwaZulu-Natal. To achieve the above-mentioned research design, the methods set out below were used.

\section{Research methods}

In order to describe a model of facilitative communication, the 
researcher had to explore the experience of nurses nursing mentally ill people in a general hospital setting as it occurs. The research methods were dealt with in four steps of theory generation in the manner set out below.

\section{Step 1: Concept analysis}

The process of concept analysis was carried out in two substeps, namely concept identification and concept definition.

\section{A. Concept identification}

Structuring theory requires that the concepts that form the theory be identified. These concepts can come from life experiences, clinical practice, basic and applied research knowledge of the literature and from the formal process of creating conceptual meaning (Chinn \& Kramer, 1991:94). During concept identification, a qualitative research strategy that is explorative, descriptive and contextual was used. This was attained through field research carried out in an urban general hospital.

\section{Field work}

As indicated above, the concepts of the model were identified through field work conducted in an urban general hospital in KwaZulu-Natal. To ensure effective data collection, a relationship was created between the institution in which data was collected and the researcher (Crabtree \& Miller, 1992:50; Van Rooyen \& Bennett, 1995:18). The researcher possessed extensive knowledge of the field, having worked as a professional nurse in this hospital from 1992-1994. The activities involved in field research included identifying and gaining access to a field in which research was conducted.

\section{Gaining entry and access}

Entry into this field of research was gained through demonstrating the results of a preliminary survey, which revealed negative attitudes among nurses working in this institution towards mentally ill people (Mavundla \& Uys, 1997:3). This indicated the need for research to the Senior Nursing Service Manager of the institution. The zonal nursing service managers were asked to be mediators between the researcher and the nurses.

\section{Ethical considerations}

The process of gaining entry into the hospital coincided with obtaining permission to conduct research from the Provincial and hospital authorities. Additional permission was also obtained from the participants in the form of consent for the interviews (Polit \& Hungler, 1991:110; Bums \& Grove, 1993:103). The consent contained all the rights to which subjects were entitled, and included the following: anonymity and confidentiality, the right to privacy, and the right to fair treatment and protection from discomforts and harm (Burns \& Grove, 1993:660).

\section{Population of the study}

In this research, the population consisted of all professional nurses working in an urban general hospital who at one time or another are involved in the nursing of mentally ill people in their departments, including the out-patient department, hospital theatre, etc. In research terms, to talk about the population is not enough: one should clearly specify the criteria ac- cording to which participants will qualify to participate in the research.

\section{Criteria for inclusion in the sample}

According to Polit and Hungler (1991:254), and Wilson (1989:261), it is important, when identifying a population, to be specific about the criteria for inclusion in the population. These criteria are referred to as eligibility criteria. The eligibility criteria for this research were as follows:

1. Both male and female participants had to be included

2. The age limit had to range between 25 and 65 years

3. The ability to converse in either Zulu, Xhosa or English was a strong recommendation

4. Subjects had to volunteer rather than being selected to participate in this research

5. An informed consent had to be obtained permitting audio recordings to be used during interview sessions

6. A relevant working experience of at least two years in a general hospital was a prerequisite; this period guaranteed that the subject was well acquainted with the atmosphere of a general hospital

7. Participants had to have nursed mentally ill people during this period in order to report personal experience of nursing the mentally ill in a general hospital

8. In order to minimise a number of variables in the study and prevent biased results from people who are already trained, participants could not be registered with the South African Nursing Council as psychiatric nurses

9. Lastly, participants had to be of the same ethnic group (i.e. Zulus); it is very important for participants to belong to the same ethnic group, since results are readily understood within a certain context, and are not value-free

\section{Sampling technique}

Once the sampling criteria had been clearly defined, a sample had to be drawn from the entire population. For the purpose of this research, a purposive sampling technique, which is one of the non-probability sampling techniques, was used. This non-probability sampling technique involves non-random sampling of subjects (Wilson, 1989:260; Polit \& Hungler, 1991:255; Burns \& Grove, 1993:243). The number of nurses interviewed was determined by saturation of data as reflected in repeating themes (Morse, 1995:147-149).

\section{Data gathering}

Two methods of data collection were used for collecting data for the research - individual phenomenological semi-structured interviews, and observations with field notes. After initial contact with nurses selected according to the sampling criteria chosen for this research, an informed consent was obtained to use a tape recorder. The date, time and place of the interview were confirmed (Chenitz \& Swanson, 1986:71-76). The following question was put to all the interviewees: "What is your experience of nursing mentally ill people in your ward?" Communication skills were used to encourage participants to verbalise their experience of nursing mentally ill people (Fielding, 1994:7; Rose, 1994:26; Newell, 1994:21).

\section{Data analysis}

The researcher made use of all the data collected in the field in the form of field notes and tape recordings in order to analyse data. The data analysis was completed by the researcher and 
another independent expert (an advanced psychiatric nursing practitioner). Giorgi's method (1985:10-19) formed the basis for analysis. The following steps were applied:

1. Data (all transcribed discussions and field notes) were coded by both the researcher and the independent expert (coder) separately from each other. The coders used bracketing (placing preconceived ideas within brackets) and intuiting (focusing on the nurses' experience of nursing mentally ill people within their environment of a general hospital setting) when reading through the transcripts and field notes for the first time.

2. The universum was taken to consist of all transcriptions and field notes.

3. The independent coder and the researcher identified major categories represented in the universum.

4. The independent coder and the researcher then underlined units of meaning that related to the identified categories.

5. The units of meaning were put into these major categories. Sub-categories within the major categories were then identified.

6. Relationships among major categories and sub-categories were identified and reflected as themes.

7. Consensus discussions between the researcher and the independent coder were held.

8. The results were then discussed as patterns of interactions of the Nursing for the Whole Person Theory.

\section{Research findings}

Since the discussion of findings is beyond the aim of this paper, a very brief discussion of themes revealed by this research is presented. The results of this research revealed four themes, namely: 1) the perception of a patient with mental illness by nurses and their knowledge of and skills for communicating with mentally ill people they encounter; 2) the experience of nurses with regard to interpersonal communication within the hospital; 3) the experience of violence by nurses; and 4) the experience of inappropriate patient behaviour by nurses in general hospital wards. These results were then controlled against available literature.

\section{Literature control}

The results were discussed in the light of relevant literature and information obtained from similar studies (Poggenpoel et al., 1994:131). This was done in order to identify the similarities and differences between this research and previous research, and the contributions of this research to previous research.

\section{Model concepts}

After the analysis of data and literature control, it became clear that there was a need to improve the way in which general hospital nurses communicated with mentally ill people, their families, other nurses and doctors. Therefore, a deductive reasoning strategy was used to identify the central concept "facilitative communication" from the research findings as the key concept of the model. Other concepts that are related to the model were also identified.

\section{Classification of concepts}

Once all concepts that form the model of facilitative communication were identified, classification of such concepts was ensured by using the survey list of Dickoff et al. (1968:434-
450). The following survey list was followed: agent, procedure, context, receiver, dynamics, and goal. After the classification of concepts was achieved, concepts were defined.

\section{B. Concept definition}

The concepts were analysed and defined, which entailed identification, analysis, definition and classification. Multiple data resources in the form of dictionaries and existing theories were used to generate and refine criteria, which included the indicators for the concepts. A reduction process was used to arrive at the essential criteria for the concepts. The definition was evaluated by the rules proposed by Copi (1986:157); Kim (1993:82-83) and Van der Steen (1993b:109). A model and borderline cases were constructed.

\section{Step 2: Creation of interrelationship statements}

The concepts identified and defined in Step 1 of this research were arranged according to their relationships through interrelation statements. Therefore, the concepts of this model did not stand in isolation, but were rather interlinked.

\section{Step 3: Model description and evaluation}

In the third step, the description of the model of facilitative communication to support general hospital nurses mobilise appropriate resources in the process of nursing mentally ill people within a general hospital setting was ensured by describing the central concepts, elements and classification of structure and process according to the method of Chinn and Kramer (1991:108). The model of facilitative communication was then given to experts in nursing and theory generation for evaluation.

\section{Step 4: Guidelines for model operationalisation}

The fourth step dealt with the development of guidelines for model operationalisation and recommendations for nursing practice, education and research. The evaluation of model operationalisation is being carried out as post-doctoral research.

\section{Measures for ensuring trustworthiness}

The research results needed to be accepted by all members of the scientific community as being authentic. Guba's model for trustworthiness was utilised to ensure the validity and reliability of this research (Lincoln \& Guba, 1985:290). The four criteria for trustworthiness are: truth value, applicability, consistency and neutrality. The truth value was ensured by applying the strategy of credibility, and applicability by applying strategies of transferability. Consistency was ensured by strategies of dependability, and neutrality by strategies of confirmability. See table 1 for the application of the model for trustworthiness.

\section{Conclusion}

In this article, the problem that led to this research is clearly 
stated based on the background knowledge serving as the prime motivation for pursuing the research. The demonstration was made as to how the theories and models were applied to provide a structure for this research. The research methods used were described comprehensively. Part 2 of the article entails a full description of a model of facilitative communication in support of general hospital nurses nursing mentally ill people.

Table 1: Strategies to ensure trustworthiness

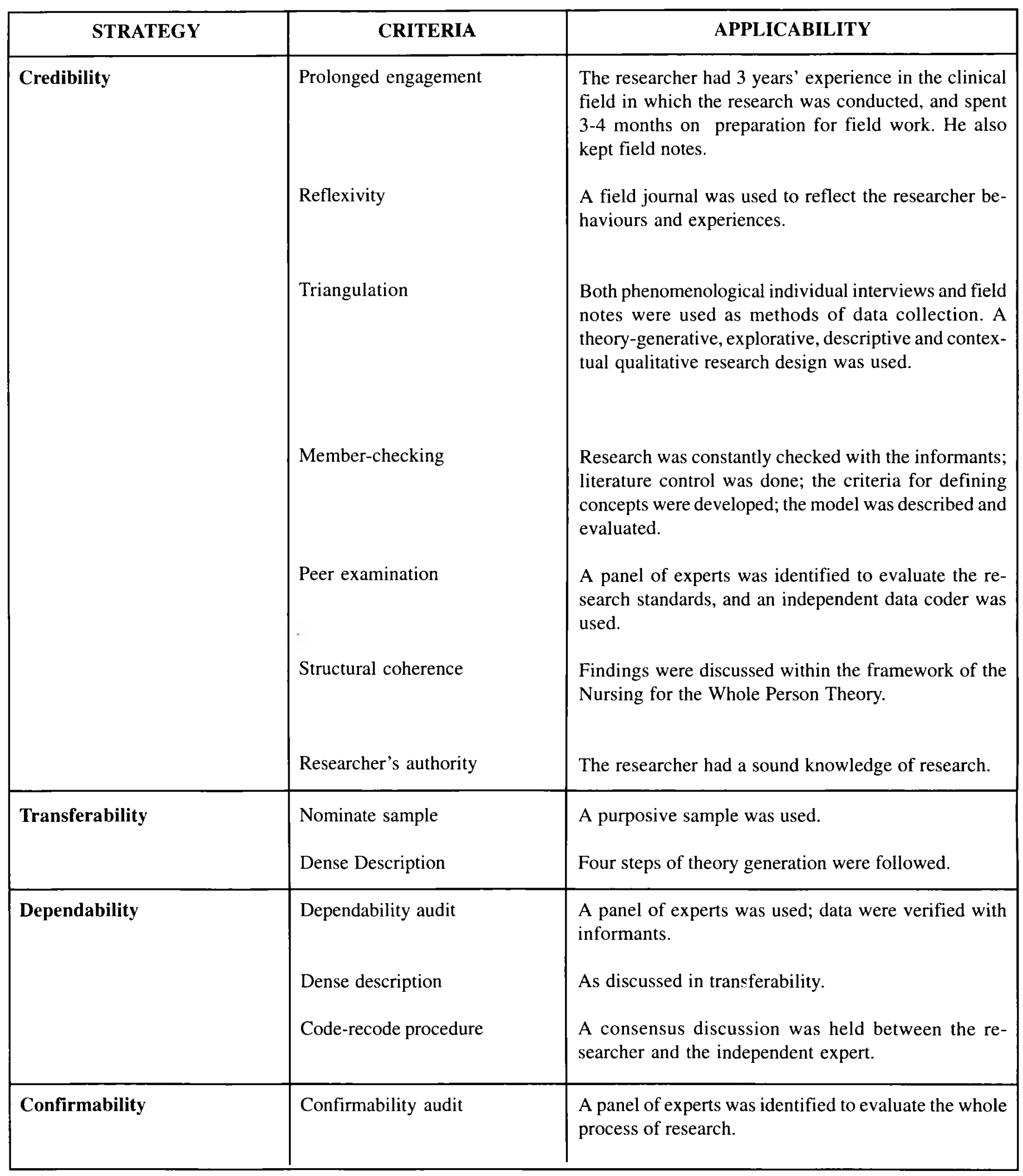




\section{References}

ABIODUN, OA 1990: Mental health and primary health care in Africa. East African Journal. 67(4) April: 273-278.

BELL, G 1991: Consultation liaison psychiatry. British Journal of Hospital Medicine. 46: 139.

BOTES, AC 1995: A Research Model in Nursing. Auckland Park: Rand Afrikaans University.

BURNS, N \& GROVE, SK 1993. The Practice of Nursing Research: Conduct, Critique and Utilization. Philadelphia: Saunders.

CHENITZ, WC \& SWANSON, JM 1986: From Practice To Grounded Theory: Qualitative Research in Nursing. Ontario: Addison-Wesley Publishing Company.

CHINN, PL \& KRAMER, MK 1991: Theory and Nursing: A Systematic Approach. Third Edition. St Louis: CV Mosby Company.

CHINNAYYA, HP; CHANDRASHEKAR, CR; MOLOY,S; RAGHURAM, A; SUBRAMANYA, KR: SHANMUGHAM,V \& UDAY KUMAR, GS 1990: Training primary health care workers in mental health care. International Journal of Social Psychiatry. 36 (4): 300-307.

COPI, IM 1986: Informal Logic. New York: MacMillan Publishing Company.

CRABTREE, BF \& MILLER, WL 1992: Doing Qualitative Research: Research Methods for Primary Care Volume 3. London: Sage Publications International Educational and Professional Publisher.

DICKOFF, J; JAMES, P \& WIEDENBACH, E 1968: Theory in a practice discipline. Part 1. Practice Oriented Theory. Nursing Research. 17(5), Sept-Oct. 1968: 415-435.

DOLINAR, LJ 1993: Obstacles to the care of patients with medical-psychiatric illness in general hospital psychiatric units. General Hospital Psychiatry. 15, 14-20.

FEINGOLD, A \& SLAMMON, WR 1993: A model integrating mental health and primary care services for families with HIV. General Hospital Psvchiatry. 15: 290-300.

FIELDING, N 1994: Varieties of research interviews. Nurse Researcher. 1(3), 4-13.

GIORGI, A 1985: ed. Phenomenology and Psychological Research. Pittsburgh, PA: Duquesne University Press.

GREEF, M \& POGGENPOEL, $M$ 1993: A model for psychiatric nursing accompaniment of a patient with a mental discomfort. Part 1. Research methods and design. Curationis, 16(1): 23-32.

KHANYILE, C 1992: Where is team-work in psychiatric hospitals? Nursing R.S.A. Verpleging, 7(9): 26-27.
KIM,JCS 1993: The Art of Creative Critical Thinking. Lanham: University Press of America.

LINCOLN, YS \& GUBA, EG 1985: Naturalistic Inquiry. Beverly Hills: Sage.

MAVUNDLA, TR 1993: The attitudes of nurses towards mentally ill people in general hospital settings. A Masters Dissertation. Durban: University of Natal.

MAVUNDLA, TR \& UYS, LR 1997: Attitudes of nurses towards mentally ill people in a general hospital setting in Durban. Curationis. 20 (2), 3-7.

MORSE, JM 1995: The significance of saturation. Qualitative Health Research. 5(2), May, 147-149.

NEWELL, R 1994: The structured interview. Nurse Researcher. 1(3), 14-22.

NKONZO-MTEMBU, LL 1994: An investigation of the opinions of black adolescents on the Esikhawini area of KwaZulu in regard to the use and abuse of alcohol. Curationis. 17(4) Dec: 50-53.

OLADE, RA 1989: The attitudes towards mental illness: effect of integration of mental health concepts into a post-basic nursing degree programme. The Advanced Journal of Nursing, 8, 93-97.

OLFSON, M 1993: The array of psychiatric services in general hospitals. General Hospital Psychiatry. 15: 277-283.

ORAL ROBERTS UNIVERSITY: ANNA VAUGHN SCHOOL OF NURSING 1990: The Nursing For The Whole Person Theory. Baccalaureate and Higher Degree Programs, National League for Nursing, August 1990. Volume I - Narrative by criteria. Tulsa, Oklahoma: Oral Roberts University: Anna Vaughn School of Nursing: 13, 136-139, 142

POGGENPOEL, M 1994: Psychiatric nurse-patient interaction facilitating mental health. Curationis. 17(1): 51-57.

POGGENPOEL, M; NOLTE, A; DORFLING, C; GREEFF, M; GROOS, E; MULLER, M; NEL, E \& ROOS. S 1994: Community views on informal housing environment: implications for health promotion. South African Journal of Sociology. 25(4): 131-136.

POLIT, DF \& HUNGLER, BP 1991: Nursing research: principles and methods. Fourth Edition. Philadelphia: J.B. Lippincott Company.

POLLIN, IS 1992: A model for counselling the medically ill: The Linda Pollin Foundation Approach Introduction. General Hospital Psvchiatry. 14S : 1S-2S.

RAND AFRIKAANS UNIVERSITY: DEPARTMENT OF NURSING SCIENCE 1992: Nursing for the whole person theory. Auckland Park: Rand Afrikaans University. 
ROSE, K 1994: Unstructured and semi-structured interviewing. Nurse Researcher, 1(3), 23-32.

SCHOENHOFER, SO 1984: Support as legitimate nursing action. Nursing Outlook. 32(4): Jul/Aug, 218-219.

SIVIK, T 1992: Education of general practitioners in psychosomatic medicine: Effects of training program on the daily work at Swedish primary Health Care Centers. General Hospital Psychiatry. 14, 375-379.

SOLOMBELA, WP \& UYS, LR 1994: Factors influencing the relapse of schizophrenic outpatients in the Kentani Area of Transkei. Curationis. 17(3) August: 24-28.

VAN DER STEEN, WJ 1993b: A Practical Philosophy for the Life Sciences. Albany, NY: State University of New York Press.

VAN ROOYEN, CAJ \& BENNETT, TR 1995: Entry into the communities: An exploratory review. Social Work Practice 2 (95) July, 17-22.

WILSON, HS 1989: Research in Nursing. Second Edition. Readwood City: Addison-Wesley Publishing Company. 